\title{
Introduction: Contours of a Research Project and Early Findings
}

\author{
Peter P. Houtzager and Anuradha Joshi
}

\begin{abstract}
1 Introduction
Early in 2005 the editors of this IDS Bulletin began developing a multi-country study to assess whether sector-wide reforms of public services, involving forms of decentralisation, pluralisation of service providers, or user/citizen participation, could enable greater accountability from below. Our interest was in forms of accountability that could expand coverage and improve the quality of public services for people who live in poverty. In the previous two and a half decades governments, first in the North and later in the South, combined these reforms in myriad ways to increase the responsiveness and quality of public services. Many of these large institutional initiatives sought, among other things, to establish direct and ongoing accountability relations between service providers and the end-users of services, or the general public. State reformers with quite different vieupoints continue to believe that such accountability relations are a critical compliment, and in some cases a substitute, to accountability from above exercised by elected officials, and ultimately voters, and by administrative hierarchy.
\end{abstract}

We decided to focus on 'critical cases', where positive outcomes of accountability from below were most likely to be found. The cases we selected, therefore, were the large urban centres of countries where reforms have been extensive and varied: São Paulo in Brazil, Delhi in India, and Mexico City in Mexico. Relative to other regions in the three countries, and to other low- or middle-income countries, these cities have more active civil societies, have a substantial history of service delivery by public agencies, and are focal points for public policy. It is in these cities where national reforms can be expected to produce changes in the pattern of state-society interactions. We chose reforms of the health and social assistance sectors, after taking into account concerns with comparability between sectors and in the reforms undertaken in each country. While these sectors may not be the best cases of the decentralisation-pluralisation-participation reforms in each city, they seemed the most comparable across the three given our concerns with their impact on accountability relations.

As we designed the study it became clear that two competing notions of accountability from below exist today. The first, inspired by the new public management (NPM) movement that first emerged in New Zealand and the United Kingdom during the 1970s, focuses on individual end-users as agents of accountability. This notion of accountability is associated with the creation of administrative complaint systems and 'choice' reforms such as the pluralisation of provision using market or pseudo-market mechanisms. The second notion of accountability is collective, or social, and emerged in new democracies during the 1990s. The agents of accountability are civil society organisations and the media, rather than individuals, and they use 'voice' to make state failures public and to trigger other forms of accountability, including those exercised by legislatures and judiciaries.

Political processes can increase accountability, expand coverage, and improve the quality of public services for people who live in poverty. The social notion of accountability from below we found the most useful for the study, because it acknowledges the severe constraints that exist on the agency of poor individuals, particularly in highly unequal societies such as Brazil, India and Mexico. ${ }^{1}$ The study, which acquired the title 'Modes of Service Delivery, Collective Action and Social Accountability in Brazil, India, and Mexico', henceforth BIM (for Brazil, India and Mexico), therefore focuses on the potential of different types of state reform to enhance social accountability rather than individual forms 
of accountability. The research traces changes in the relations between collective agents (or actors) representing the poor, policymakers and service providers in the areas of healthcare and social assistance

The study examines three ideas. First, an idea which is gaining currency: that the participation of actors that represent poor and underserved communities in policy negotiations and in direct accountability relations with providers are critical to extending basic public services to those communities. Second, the idea that derives from institutionalist analyses: that different types of institutional reforms of public services will create distinct opportunities and barriers to participation in policy and accountability. And third, the idea that emerged from the slow accretion of when actors who represent poor and underserved communities have been a party to negotiating reforms knowledge about network analysis: that local actors will be more likely to establish relations of social accountability with service providers in their communities when they are part of larger networks of actors who negotiate public policy. We agreed, finally, that the study should also look at outcomes: does social accountability lead to better service coverage and quality?

The findings of BIM's first year of fieldwork are presented in this IDS Bulletin. The articles are case studies that focus on the role of civil society actors (or absence thereof) in the design of sectoral reforms and the possibilities of social accountability that accrue from this role. In addition to large institutional reforms in social assistance and health, the articles cover education reform in India as well.

Early findings from the research emphasise that the likelihood of social accountability increases substantially when actors who represent poor and underserved communities have been a party to negotiating reforms; when such actors succeed in engineering some form of institutional fit to state decision-making centres which ensures their access to policymakers over the medium to long term; and when alliances between public sector reformists and civil society actors are formed.

The first set of articles in this IDS Bulletin introduces the study and provides summary statements of important conceptual and methodological issues, as well as some of the overarching findings from year one. Joshi provides a conceptual exploration of social accountability and identifies its empirical referents. Gurza Lavalle highlights the contextualised nature of the politics of reform in each of the countries and cities, linking local political dynamics to the reform options that have been chosen. In their discussion of the study's methodology, Houtzager and Acharya make a link between the institutional environment that supports governance research and the study's research design. MacPherson challenges the NPM view of end-users as generic agents of accountability, arguing that it is women who, within the household division of labour, are responsible for accessing public services such as health and education, and that women's agency is constrained in ways different from that of men.

The second set of articles examines social accountability in social assistance services. Here the focus is on anti-poverty programmes: the provision of subsidised food and kerosene in Delhi through the Targeted Public Distribution System (TPDS), and the new type of income grant or cash transfers in São Paulo and Mexico. Pande focuses on the successful accountability role of advocacy non-governmental organisation (NGO) Parivatan in Delhi's TPDS, which reduced corruption and increased access to the programme. She pays close attention to Parivatan's use of Right to Information litigation. Houtzager examines the new Minimum Family Income Guarantee Programme (known as Renda Mínima) in São Paulo, a predecessor of the national Bolsa Familia programme, and argues that the silence of civil society in the programme's formulation and social accountability was manufactured by policymakers. Hevia explores the ultimately failed effort of the conditional cash transfer programme Oportunidade in Mexico to eliminate the intermediation of 'bad civil society' and to encourage direct citizen participation.

The next set of articles identify the extensive but varied roles civil society actors have played in positively evaluated sector-wide reforms in health and education. Dowbor identifies the central role played by the public health Sanitarista movement in the creation of Brazil's Unified Health System (Sistema Único de Saúde, SUS) which universalises public healthcare. The influence women's advocacy NGOs of the National Forum for Health and Population Policy (Foro Nacional de Salud y Políticas de Población) have had on the reform and universalisation of reproductive health is the subject of GómezJauregui's contribution. Chakrabarti explores the 
bagdari programme in Delhi, and shows how this reform to institutionalise participation in urban governance has fallen under the domination of middle-class organisations, potentially at a cost to the poor. Mehtta examines the multiple roles civil society organisations have played in the delivery and accountability of elementary (public) education in Delhi, including through the Right to Food Campaign.

Concluding this IDS Bulletin, Jayal offers a final reflection on the potential contribution of BIM to theorising social accountability, and points out some important ambiguities in the notion of social accountability.

\subsection{Social accountability}

In this IDS Bulletin social accountability is understood as an ongoing and collective effort to hold public officials and service providers to account for the provision of public goods which are existing state obligations, such as primary healthcare, education, sanitation and security. This accountability is exercised by collective agents such as neighbourhood associations, social movements, advocacy NGOs, and media organisations through non-electoral mechanisms (Smulovitz and Peruzzotti 2000). The core strategy of social accountability is making state failures in meeting existing legal obligations public, including the failure to provide service coverage to the poor or to provide services consonant with existing legal standards or procedures. Collective actors use institutional and non-institutional channels to monitor state activity or inactivity. By making state failure public, they impose reputational and political costs on the agencies involved and often trigger other forms of accountability, including through the courts, ombudsmen, public accounting or auditing bodies, or legislative oversight (Peruzzotti and Smulovitz 2006).

One of the advantages of social accountability, Jayal points out, is that 'it can be catalysed on demand as and when the situation requires'. Compared to the very broad and periodic (or discontinuous) nature of electoral accountability, social accountability provides a sharper, or more targeted, form of accountability focused on a particular set of issues and a specific set of (elected or non-elected) actors. Because it can be used 'on demand', the timing of accountability efforts, such as public exposure of failures or wrongdoing, or activating other forms of accountability, becomes a valuable political and strategic asset.
Joshi makes two important distinctions in her contribution. First, she distinguishes between the accountability to individuals advocated by NPMinspired reforms, such as the Citizen Complaint System of Mexico's Oportunidades, and social accountability to collective agents that have a broad public interest. The latter is well exemplified by the Right to Information Campaign and the advocacy NGO Parivatan, which sought to improve access to the Targeted Public Distribution System (TPDS) in Delhi. This distinction is important because it acknowledges the power disparities between poor individuals and public officials, and the poor and nongovernment service providers, in most social contexts. It focuses attention on what agency poor communities do have: the rightousness and/or legality of their claims and the power of numbers. ${ }^{2}$ For improving the coverage and quality of public services in poor and underserved communities, social accountability is therefore particularly relevant.

Second, she stresses the distinction between participation in policy deliberation and social accountability. While some researchers refer to both as social accountability, Joshi argues convincingly for the need to separate them analytically. The analytic distinction is important because not only are very different processes involved, with distinct dilemmas and obstacles, but there may in fact be a conflict or tension between these two roles. Can civil society organisations that are parties to policy negotiations also act as forceful watchdogs of the implementation of these policies, and act as agents of accountability? That question is an important one and the answer is not obvious, and certainly not simple. Without the analytic distinction it cannot be asked

One of the critiques of social accountability is that it lacks teeth. Civil society organisations can force state officials to be 'answerable' for their action or inaction but, critics suggest, they have no ability to impose sanctions and force compliance - that is 'enforcement' capacity (Schedler 1999). A critical feature of social accountability, as it is emerging out of the practices of civil society actors, is its linkage to other forms of accountability to produce enforcement, however. Publicity - i.e. making state failure public - and litigation through the court system trigger forms of accountability from above, by other state institutions. Publicity has triggered investigations not only by legislative bodies, but also by independent regulator or auditing bodies, as well 
as public prosecutors such as those belonging to Brazil's Ministerio Público. Litigation, including that involving the Right to Information, has played a particularly prominent role in India (Joshi, Pande, Mehtta, and Jayal, this IDS Bulletin).

\section{The study: making services responsive to the poor}

The study from which this IDS Bulletin's articles are drawn traces the interaction of collective actors who represent users in poor urban communities, policymakers, and providers of services at three distinct points in time. The study's baseline is the pattern of relations that was in place in the period immediately prior to the reforms. Having established this baseline we then examine what role collective actors played in the negotiation of the reforms themselves. And finally we examine the pattern of relations in the post-reform period. This temporal analysis is conducted for reforms in healthcare and of social assistance, because they are directly related to poverty reduction, have seen significant institutional reforms in the mid-1980s to the early 2000s, and represent distinct types of public goods.

As Gurza Lavalle notes in this IDS Bulletin, the reforms undertaken by national and sub-national governments are tremendously varied and reflect the effects of contextual political processes. Measured against the policy packages advocated by bi- and multi-lateral organisations, and widely debated in the literature on public sector reform, the institutional changes undertaken in Brazil, India, and Mexico appear hopelessly heterodox. Mindful of this variety and complexity, we have nonetheless sought to select national-level reforms that, in broad terms, embody voice or choice-oriented logics, and then specific programmes executed by city administrations that attempt to make these reforms land locally. ${ }^{3}$

In Brazil, health reforms have been voice-oriented universalisation of access to healthcare with the Unified Health System (SUS) has been accompanied by significant decentralisation and the creation of deliberative governance councils in which collective actors representing diverse interests are guaranteed seats. The largest component of the social assistance reforms has, in contrast, followed a choice-logic involving monthly income grants to poor families, through the federal Bolsa Familia programme and municipal programmes such as Renda Mínima. In Mexico reforms in both sectors have largely been choice-oriented: the staccato health sector reforms have combined decentralisation and marketenhancing institutional change, and social assistance has shifted towards targeted and conditional income transfers. Nonetheless, in the case of reproductive health there have been important voice-enhancing institutional changes. In India the most significant institutional changes have been broad reforms of the state, such as decentralisation (through the 74th constitutional amendment) and the Right to Information Act, which have potentially significant implications for social accountability of the health and social assistance sectors. These reforms are in part voice-oriented, as they seek to enhance citizens rights and leverage vis-à-vis public bureaucracy.

BIM does not attempt to make direct comparisons between specific institutional changes that have taken place in the countries' respective and highly varied social assistance and health sectors. Nor does it attempt direct comparison of specific programmes such as TPDS and Renda Mínima. The study makes comparisons of a more general order: it compares underlying processes that, in different contexts and sectors, produce similar types of state reforms which we summarise as voice or choice orientations - and it compares types of changes in the interaction between state and civil society actors that result from these different reform processes.

\subsection{The hypotheses}

The hypotheses we explore through the comparisons - i.e. at a relatively high level of generality - are four.

1 Reforms aimed at enhancing voice (decentralisation and institutionalised participation) are more likely to enhance the capacity of networks of collective actors representing poor communities to engage in forms of social accountability. Conversely, choice-oriented reforms are more likely to undermine that capacity.

2 Reform processes in which networks of collective actors representing poor communities participate in negotiating reforms are more likely to create effective and durable accountability relations between such actors, on the one hand, to policymakers and, on the other, to providers who must change their behaviour.

2a Participation in policymaking creates incentives for, and enhances the capacity of, these collective actors to monitor and engage with policymakers and providers. 
2b Participation in policymaking allows collective actors to construct their fit with emerging institutions - i.e. establish a degree of embeddedness in public institutions - to facilitate future access, thereby lowering the costs of social accountability over the medium and long term.

3 Networks of collective actors that cut across class, such as alliances of middle-class NGOs and membership associations or community groups, have greater capacity to engage in forms of social accountability of both policymakers and of local providers. Where networks are linked to broader political movements this capacity is further enhanced.

3a The actors who establish accountability relations with local providers are likely to be community or membership organisations that have not, themselves, participated in the policy process. If they are part of the same network of actors who do participate in the policy process, which will tend to be more professionalised (and possibly middle class), then local accountability will be enhanced.

4 The exercise of social accountability by collective actors representing poor communities increases the likelihood of uptake of reforms by providers, as well as by communities (who then create demand for services).

\subsection{Moving towards 'big' governance research}

Governance research takes many forms but its central ambition is to identify the complex processes of change that contribute to better governance, and to draw broad lessons about these processes that will hold for a range of countries or contexts. The research designs that are particularly well suited to address significant governance questions that face the international development community, Houtzager and Acharya argue in their contribution, are interdisciplinary, process-oriented, and multicountry or multi-region comparisons. Such research is logistically complex, requires relatively high levels of funding, and by social science standards long timeframes. The structure of national universities and research institutes, as well as that of many international organisations, they point out, instead favour disciplinary research, conducted within relatively short timeframes, using either quantitative snapshots (even in the case of panel data) or case studies built on distinct analytic or fieldwork models.
In their presentation of the study's methodology, Houtzager and Acharya identify a set of institutional innovations that make possible a move towards the type of 'big governance research' that begins to meet the information and knowledge requirements of contemporary governance questions. BIM's methodology combines analysis at three different levels. The first level consists of narrative accounts of the political process of (national) reforms in health and social assistance sectors, and case studies of a municipal-level programme in each sector that embodies the essence of these reforms. The second level uses network analyses to identify changes from the pre- to post-reform period in the capacity of civil society actors, as a consequence of the reforms, to negotiate policy. The capacity to negotiate policies, the authors believe, resides in part in the types of relations civil society actors establish amongst themselves, and between their network and policy makers. The third level differs from the others in that it is concerned only with the post-reform period and whether social accountability contributes to improved services. It focuses on relations of social accountability between local community actors and providers across regions of each city, and uses crosssectional analysis of social accountability and service provision in health and social assistance.

The innovative organisational and funding model for governance research developed by the Centre for the Future State (CFS) has provided the institutional foundation for this comparative and multi-level research design. The CFS has made it possible to form well-coupled research teams - that is, teams in which researchers based in disparate countries are able to make a sustained collective investment in designing and conducting research. Such teams are able to undertake multi-country studies that feature a single analytic framework and a coherent comparative methodology, and in which members conduct fieldwork in their respective countries in rigorously comparable ways.

\section{Early lessons, and a puzzle}

A key idea framing the BIM study and the articles in this IDS Bulletin is that opportunities for social accountability can change substantially with public sector reforms, sometimes in unexpected ways. Reorganising how services are delivered, or even the nature of the service itself, as in the case of antipoverty programmes examined here, can lead to the emergence of new actors and institutions, 
strengthen or weaken existing actors, and consequently can alter the alliance possibilities of the urban poor. Here the authors want to highlight a few lessons, and a puzzle, that appear prominently in several of the articles in this IDS Bulletin.

\subsection{Engineering institutional fit}

The articles in this IDS Bulletin suggest collective actors who succeed in engineering some form of institutional fit to the state's decision-making centres increase their ability in the medium to long term to engage in social accountability (Hypothesis 2b). This institutional fit can take many forms, from participatory governance councils for health in São Paulo, designed in part to enhance the leverage of the health movement, to the Inter-institutional Group on Reproductive Health designed in part to provide Mexico's women's movement a privileged position in designing reproductive health policy and monitoring implementation. ${ }^{4}$

By way of contrast, the anti-poverty programmes Oportunidades and Renda Mínima lack such institutional mechanisms for organisations representing intended beneficiaries. Hevia and Houtzager both note that these programmes were designed in part to limit or eliminate the influence of organisations that have historically mediated relations between the state and the poor. Oportunidades instead created, from above, community assemblies for the participation of individual citizens and a Citizens Complaints System. As Hevia observes, however, how can an indigenous woman who speaks little or no Spanish denounce '... the municipal authority who forces her to attend party meetings or who threatens to cut off her benefits if she does not vote in accordance with this or that party?'. In the case of Renda Mínima no channels for participation were created - individual beneficiaries can only lodge complaints with the municipal administration, or seek the mediation of local politicians or other influential persons.

In the cases examined in this IDS Bulletin, civil society actors have been more likely to engineer some form of institutional fit during moments of significant state reform. The actors who were involved in the policy process during reform moments were in a privileged position to engineer these new institutions in ways that enable their medium- to long-term role in both policy and social accountability. Notably, the Sanitaristas in Brazil and women's movement in
Mexico drove the reform process from the start, whereas no such collective agents were involved in the creation of Oportunidades or Renda Mínima. Differently, Pande shows that the advocacy NGO Parivatan, as a consequence of its social accountability role in the TPDS programme, has been invited to take part in policy discussions. This new role has not, however, been accompanied by the creation of governance institutions that ensures its access to policymakers over the medium to long term. Parivatan provides a test case in this regard: will it be able to institutionalise its role, given there was no opportunity to engineer institutional fit when the original Public Distribution System (PDS) was created, nor during the reforms that led to TPDS.

\subsection{Alliances across the public-private divide}

Studies of public sector reform often highlight the obstacles public sector professionals, and their trade associations in particular, pose to major institutional change. In several of our cases, however, it is groups of reformist public sector professionals who played the central role in pushing for reforms that increased service coverage and quality. In some cases these professional groups became important allies to the movements of the urban poor. And at least in one case, the creation of the universal healthcare system in Brazil, such a professional group went so far as to stimulate the formation of an urban health movement that would seek the expansion of health coverage to poor regions. The Sanitarista public health movement, made up overwhelmingly of public sector healthcare professionals, not only led the process that created the country's Unified Health System (SUS), Dowbor shows in her contribution, but actively organised poor urban areas of São Paulo to make demands for the implementation of the new system in those areas. Public sector health professionals in Mexico have similarly played a critical role in the more piecemeal reforms of that sector (Blanco-Mancilla 2007).

The entry of prominent civil society leaders into the state itself to help design and/or implement the reforms is an important part of constructing alliances that cut across the public-private divide in some of our cases. In Mexico for example, the alliance between women's organisations and the Health Secretary was established when the latter was still at the head of a prominent civil society organisation. When Julio Frenk was invited to become Health Secretary, he brought his previous relations with 
members of the National Forum into the state and helped establish an alliance across the public-private divide that played a key role in the expansion of women's reproductive healthcare (Gómez-Jauregui, this IDS Bulletin).

In most of these cases reformist public sector professionals created their own networks, and sometimes organisations, that ran outside of their labour organisations. This suggests a function division of labour between reformist organisations concerned with improving public sector performance and labour unions concerned with negotiating employment terms and conditions.

\subsection{Anti-poverty policies: eliminating the mediation of 'bad' civil society}

Social policy in Latin America and India has until recently focused almost exclusively on workers in the formal sector - unemployment, disability, and old age pensions, as well as healthcare was largely restricted to workers with formal employment relations. Two of the articles in this IDS Bulletin address the profound change that has occurred in this regard in Latin America, with the creation of conditional cash transfer and minimum income guarantee programmes. Programmes such as Renda Mínima, Bolsa Família, and Oportunidades now extend a minimal form of social protection to lowincome families that depend on the income of workers outside of the formal labour market. The programmes provide poor families monthly income transfers, conditional on fulfilling obligations such as class attendance of all school-aged children.

In contrast to the experience of health discussed above, the profound expansion of the state's role in combating poverty has occurred with little or no involvement of organisations representing poor communities. The processes through which the programmes were designed sought to exclude the participation of civil society actors. The programmes attempt to establish a direct relation between the state agency that executes the programme and the beneficiary families. One of the goals of doing so is eliminating the mediation of what is considered 'bad' civil society - that is, clientelist and authoritarian civil society organisations that have historically mediated relations between the state and the poor. Arguably both 'bad' and 'good' civil society actors have been kept at arms length as a consequence and there is therefore an absence of effective collective agents who can monitor execution, demand improvements or rectification of error, and ensure some form of public budgetary accounting.

\subsection{Mutually reinforcing or exclusive governance roles?}

In her contribution to this IDS Bulletin, Jayal raises one of the principal puzzles faced by advocates of civil society organisations' role as agents of social accountability. NGOs, membership associations, and community groups increasingly play multiple governance roles, some of which appear to be mutually reinforcing but others appear to be mutually exclusive. In broad strokes, civil organisations are being called upon, or have called upon themselves, to exercise four distinct governance roles that stand in varying degrees of tension to each other: participation in policy negotiations, co-administration of public services, delivery of public services, and finally social accountability.

Participation in policymaking is often seen to threaten the autonomy of civil society actors, and hence compromising their ability to engage in social accountability. The BIM study hypothesises the opposite: participation in policy negotiation and social accountability are mutually reinforcing. Actors who participate in policymaking will have a powerful interest in seeing the resulting policies implemented, and greater capacity to monitor such implementation. Where these policy actors are networked to local or community organisations that can establish direct accountability relations with providers, the prospects for effective social accountability, and possibly improved service coverage and quality, are greater. Pande points out that the causal arrow for Parivatan is in the reverse direction - recognition of one's role in social accountability can lead to involvement in policymaking. At least in our cases, there may therefore be a larger mutually reinforcing dynamic between policy negotiation and social accountability than we had originally hypothesised.

Are the service delivery and social accountability roles mutually reinforcing or, virtually by definition, mutually exclusive? Actors who deliver services under public contract or as part of public-private partnerships cannot engage in social accountability of their own relation to end-users or the general public. At best they can engage in self-regulation, or come under the oversight of a public but independent regulatory body. The dynamics of accountability are different, 
however, in the relation of non-government providers to the state. When state agencies contract out service delivery they in effect create a new layer of actors with a direct interest in expanding and sustaining that service - that is, a 'lobby' of providers. This provider-lobby has a set of interests that partially overlap with those of people living in poverty. For example, ensuring that the entire budgetary allocation for a service is actually spent by the administration is in the interest of both the lobby and end-users, as is increasing the number of qualified staff in primary healthcare units that non-profit providers manage. The normative position many nonprofit providers have in favour of their clients reinforces the potential for alliances between this layer of organisation and those of the poor. Not infrequently providers engage in forms of assumed representation of their client base when the latter are unorganised and/or lack access to the state. ${ }^{5}$

The most complex case of the puzzle Jayal has identified, however, is that of civil society organisations that are involved in three or four of these roles, sometimes as members of new participatory governance institutions. In São Paulo, for example, civil society organisations have constitutionally guaranteed seats on the municipal governance councils, in the areas of health, education, social assistance, and child and adolescent. These councils combine policymaking, oversight,

\section{Notes}

1 See Mainwaring and Welna (2003) and Schedler et al. (1999), and for OECD countries see Cain et al. (2003).

2 This distinction is not universally made. The World Bank, for example, employs a notion of social accountability in its programmes and studies that obscures these substantial differences between the agency and possibilities of individual and collective action (cf. Ackerman 2005).

3 The two poles have also been described as 'neoliberal' and 'deliberative' (alternatively: management, and accountability roles. In the case of education in Delhi, Mehtta's contribution traces how a substantial number of education NGOs have been involved in the designing, implementation, and monitoring of the 2002 education reform, which seeks to guarantee universal access to public education. Under the new Universal Elementary Education Programme (Sarva Shiksha Abhiyan, SSA) NGO-run Learning Centres prepare young children from poor families for entry into the public school system. Mehtta notes a potentially interesting development in the programme: the monitoring of the Learning Centres by public bodies made up of School Welfare Committees representing teachers and parents, government education officials, and implementing NGOs.

\section{Conclusion}

Jayal's concern about the potential tension between different governance roles provides a good end point for this Introduction. It in effect defines an important research frontier as our knowledge of social accountability advances. The contributions to this IDS Bulletin, and the BIM study, are a first at developing a more nuanced and empirically grounded understanding of the mutually reinforcing or exclusive nature of these civil society governance roles, and of the new governance institutions that attempt to combine these roles in innovative but possibly contradictory ways.

co-governance or stakeholder governance) (cf. Ansell and Gingrich 2003; Evans 2005).

4 The privileged and institutionalised access to the state that some actors are able to engineer greatly lower the cost of obtaining information about state activity and of engaging in policy negotiations. For a discussion of institutional fit, see Houtzager (2003) and Joshi in this IDS Bulletin.

5 See Houtzager and Gurza Lavalle (forthcoming) and Gurza Lavalle et al. (2005). 


\section{References}

Ackerman, John M. (2005) Social Accountability in the Public Sector: A Conceptual Discussion, World Bank Social Development Papers 82, Washington DC.: World Bank

Ansell, Christopher and Gingrich, Jane (2003) 'Reforming the Administrative State', in Bruce E. Cain, Russell J. Dalton and Susan E. Scarrow (eds), Democracy Transformed? Expanding Political Opportunities in Advanced Industrial Countries, Oxford: Oxford University Press

Blanco-Mancilla, Georgina (2007) The Health Sector in Mexico: Overview, background paper for the study 'Modes of Service Delivery, Collective Action, and Societal Regulation: Making Public Services Responsive to the Poor in Brazil, India, and Mexico', Brighton: IDS

Cain, Bruce E.; Dalton, Russell J. and Scarrow, Susan E. (eds) (2003) Democracy Transformed? Expanding Political Opportunities in Advanced Industrial Countries, Oxford: Oxford University Press

Evans, Peter (2005) 'Harnessing the State:

Rebalancing Strategies for Monitoring and Motivation', in Matthew Lange and Dietrich Rueschemeyer (eds), States and Development: Historical Antecedents of Stagnation and Advance, New York: Palgrave Macmillan

Gurza Lavalle, Adrián; Houtzager, Peter P. and Castello, Graziela (2005) In Whose Name? Political Representation and Civil Organisations in Brazil, IDS Working Paper 249, Brighton: IDS
Houtzager, Peter P. (2003) 'Introduction: From Polycentrism to the Polity', in Peter P. Houtzager and Mick Moore (eds), Changing Paths: International Development and the New Politics of Inclusion, Michigan: University of Michigan Press

Houtzager, Peter P. and Gurza Lavalle, Adrián (forthcoming) 'The Paradox of Civil Society Representation: Constructing New Forms of Democratic Legitimacy in Brazil', in Olle Törnquist (ed.), Rethinking Popular-Democratic Representation Mainwaring, Scott and Welna, Christopher (eds) (2003) Democratic Accountability in Latin America, New York: Oxford University Press

Peruzzotti, Enrique and Smulovitz, Catalina (2006) 'Societal Accountability: The Other Side of Control', in Enrique Peruzzotti and Catalina Smulovitz (eds), Enforcing the Rule of Law: Social Accountability in the New Latin American Democracies, Pittsburg: University of Pittsburg Press

Schedler, Andreas (1999) 'Conceptualizing Accountability', in Andreas Schedler, Larry Diamond and Marc F. Plattner (eds), The SelfRestraining State: Power and Accountability in New Democracies, Boulder, Co: Lynne Riener

Schedler, Andreas; Diamond, Larry and Plattner, Marc F. (eds) (1999) The Self-Restraining State: Power and Accountability in New Democracies, Boulder, Co: Lynne Riener

Smulovitz, Catalina and Peruzzotti, Enrique (2000) 'Societal Accountability in Latin America', Journal of Democracy 11.4: 147-58 